\title{
Shift from PLM to SLM: A Method to Support Business Requirements Elicitation for Service Innovation
}

\author{
Margherita Peruzzini, Michele Germani, and Claudio Favi \\ Polytechnic University of Marche \\ via Brecce Bianche 12, 60131 Ancona \\ \{m.peruzzini,m.germani,c.favi\}@univpm.it
}

\begin{abstract}
PLM is a widely recognized approach to reduce time to market, increase process efficiency and control product lifecycle. However, serviceoriented management is becoming increasingly popular to create new business infrastructures able to self-organize tangible and intangible manufacturing assets in a distributed and interoperable way [1]. The final scope is to manage not simply the Product but also Services along the value chain. The great modern challenge is the implementation of such a service-oriented approach and the shift from PLM (Product Lifecycle Management) to SLM (Service Lifecycle Management). This paper proposes a structured method to define a TO-BE service-oriented scenario and elicit business requirements towards the creation of an SLM-based ecosystem. A case study is developed in collaboration with an Italian company leader in household appliances. It focuses on washing machine, investigates AS-IS and TO-BE business scenarios by adopting Functional Analysis and Business Use Cases (BUC), and then defines the necessary business requirements to implement a service-based approach and create the future SLM ecosystem.
\end{abstract}

Keywords: SLM (Service Lifecycle Management), Virtual Factories, SSME (Service Science, Management and Engineering), Ecosystem Collaboration.

\section{Introduction}

Service innovation has been recently identified as the most promising way to evolve market trends and develop robust innovative roadmaps for the modern globalised society. It aims to involve organizations, public bodies, tertiary service providers and customers in a unique business framework.

Research on SSME (Service Science, Management and Engineering) [1] has identified two main issues: the creation of the so-called Factories of the Future able to adapt and extend SSME concepts to traditionally product-oriented enterprises, and the definition of a service-oriented platform for SLM (Service Lifecycle Management) to transform current hierarchical supply chains into collaborative open ecosystems. It implies defining the business requirements according to the target market and defining the best processes to support collaborative innovation in a secure industrial environment. Subsequently, a collaborative open ecosystem can be realized to translate 
business ideas into real services by means of FI (Future Internet) tools. Requirements elicitation (RE) is particularly critical because of the huge quantity of implicit knowledge to be elicited and the variety of actors involved. As a consequence, RE needs to be faced in a structured and rigorous way.

This paper presents an industrial case study where a big Italian company (Indesit Company) producing white goods tries to follow the service innovation approach and shift from PLM to SLM. During the study, a structured methodology based on Functional Analysis and Business Use Case (BUC) is adopted. Functional Analysis is used to deepen and formalize the AS-IS scenarios referring to those products and services currently offered on the market. Subsequently, functional models are translated into BUC models and TO-BE use cases are depicted in collaboration with the company. Participatory design techniques are adopted to define the AS-IS scenario and to carry out the TO-BE BUC analysis. Investigation of the TO-BE diagrams allows system requirements to be elicited in a precise and clear way and weighted according to the needs of the involved business partners. It finally demonstrates that only a correct RE strategy can assure the realization of a robust SLM approach and the implementation of a successful collaborative ecosystem.

The paper is structured as follows: section 2 illustrates the research background in service innovation, service ecosystems and RE techniques; section 3 describes the adopted method to support the transition from PLM to SLM; section 4 presents the industrial case study, describes method application and the main experimental results; section 5 provides closing remarks and presents the future work.

\section{Background}

\subsection{Service Innovation and Service-Based Enterprises}

Service innovation can be defined as a "new or considerably changed service concept that leads to one or more new or renewed service functions" [2]. This definition covers both technological and non-technological innovations, which mainly arise from investment in tangible and intangible inputs. Innovations can for instance be new solutions in the customer interface, new distribution methods, novel applications of technology in the service process, new forms of operation with the supply chain or new ways to organize and manage services.

However, several approaches to service management exist. According to [3], it's almost impossible to provide a short definition of service, which is valid for the whole service sector, but that it's possible to gather some common aspects of services in one definition with a specific approach. This paper focuses on manufacturing applications. In this context, a service is an intangible asset that is present at a specific time and location to guarantee the execution of some type of action, upon the occurrence of a certain triggering event, in the interest of another [4]. Furthermore, a service is also a transaction where one party grants temporary access to the resources of another party in order to perform a certain function and a related benefit. Resources may be human workforce and skills, technical systems, information, consumables, land and others [5].

Services constitute a source of innovation whatever the sector of activities. Manufacturers currently sell products and propose additional services to their customers or 
even sell product as a service. A Product-Service has been defined as a service supplied in addition to a product increasing its value for the customers [6]. More recently, a Product-Service has been defined as a value proposition that consists of a mix of tangible products and intangible service designed and combined so that they are jointly capable of fulfilling integrated, final customer needs, while a Product-Service System (PSS) as the product-service including the network and infrastructure needed to realize a Product-Service [7]. Furthermore, an Industrial Product-Service System (IPS2) is characterized by the integrated and mutually determined planning, development, provision and use of product and service shares including its immanent software components in Business-to-Business applications and represents a knowledgeintensive socio-technical system.

In this context, one pillar of service innovation is service differentiation (Servitization), which consists of the ability to offer a wide range of services connected to the same product. Servitization comes from the idea of extended products [8] and is based on adding value by incorporating services into a core product: the Product is the physical item offered on the market, the Product Shell describes the tangible "packaging" of the product and a set of Supporting Services as intangible additions, which facilitate or support the use of the product. Differentiating the offered services allows a different positioning of the Extended Product on the market. At this point, two scenarios can be realized: Product+Service and Product2Service. The Product+Service scenario describes the simultaneous offering of the tangible product (Core Product + Shell) extended with proper tailored services. The Product2Service scenario is sharply decoupling manufacturing of goods and selling of services, where in most cases physical goods remain the property of the manufacturer and are considered as an investment, while revenues come solely from the services. The first sees services as a means of creating a competitive advantage by adding value in the customer's view and making products more difficult to imitate, creating a "win-win situation". The latter sees services as potentially replacing products and is concerned with environmental, rather than financial, motivation.

Both types of scenarios require a novel business model and, consequently, proper system architectures to realize the above-mentioned service-oriented approach. On one hand, industries need to be reorganized in order to support the overall service lifecycle in connection with the existing product lifecycle. It means shifting from a traditional PLM approach to a new SLM approach. On the other hand, companies have to develop and implement new business models based on global collaboration, where design and production networks extend the traditional model to create collaborative structure (e.g. Virtual Organizations, Virtual Enterprise) [9]. The enterprise model will change by moving from a traditional single enterprise producing products to a virtual enterprise providing services around the product as a temporal association of several companies and customers. PLM supports the traditional manufacturing system well, but an SLM approach is required to properly support service-oriented virtual enterprises.

SLM concept aims at managing all service data relating to its design, implementation, operation and final disposal. It adopts the ISO 15704 (2000) standard defining generic entity/system life cycle phases and evolution in time, and exploits the basic 
concepts from several enterprise architectures and methodologies (e.g. CIMOSA, PERA, GERAM, GRAI). As a result, a Service lifecycle can be defined via the following phases: service system definition, requirements definition, architecture design, system service implementation, operation, and decommission [10].

\subsection{Requirements Elicitation to Support SLM}

Requirements elicitation (RE) is a crucial activity when talking about the collection and documentation of needs regarding what a particular product-service should do or be like. Indeed, the success of such a product-service heavily depends on the gathered requirements and how these address the needs of the stakeholders [11]. For such a task traditional requirements elicitation or creativity techniques can be applied [12].

To be successful RE needs to start from the analysis of users' requirements: they first have to be captured and then translated into more formal system requirements. A short overview of the most common RE techniques is proposed by [13]. However, traditional approaches do not seem to be very suitable when aiming to elicit requirements for innovative services and/or products. In particular, they lack in understanding the tacit users' knowledge and formalizing the user-centred processes. On the contrary, service innovation usually aims to conceive completely new services that did not exist before. These might be new for the company, for the market or even for the world. In this context knowledge elicitation is difficult.

Furthermore, two main issues need to be faced: the transition from manufacturing industry (product-based) to service ecosystem (service-based), which implies adopting a product-based perspective; and the investigation of customer needs to properly define the service-based functions. The former issue can be supported by a wellknown approach used for RE in industrial surveys, the so-called multi-level analysis. The latter can be addressed by the Business Use Case (BUC) analysis. Multifunctional analysis considers the model as a simplified scheme, which underlines the main product characteristics to understand and forecast its behaviour. It aims at a substantial reduction of the number of solutions and makes heuristic simplifications on two spaces (behaviour and functional) [14]. BUC analysis is based on the definition of a business use-case model, which defines a goal-oriented set of interactions between external actors and the system under consideration [15-16]. The combination of the two techniques allows the product complexity and the variations management in configuring new solutions to be easily represented and the business characteristics to de defined from the users' point of view.

\section{From PLM to SLM: The Research Approach}

The research approach is based on the combination of traditional RE techniques with functional analysis to explicit the requirements of new service-product solutions. Then, the adoption of BUC analysis provides clear and easy-to-read models to conceive the new service offer. It represents a usable and simplified way to model the transition from product manufacturing to service provisioning and to support the shift 
from PLM to SLM in industry. The proposed methodology can be synthesized in 5 main steps:

Step 1. Investigation of the AS-IS business scenario by adopting Participatory Design techniques and dual perspective in tacking the problems, considering both the design process and service use. Participatory Design directly involves the business end-users as well as the customers to depict the actual situation that is strongly product-oriented. It aims to understand how the actual product is designed within the company, how it is considered and valued, how it is perceived by the customers, and how much it is valued by the market. The dual viewpoint assures the performance of a wider investigation with regard to the concept/design process and the service level of use.

Step 2. Definition of the AS-IS use cases and formalization by combining functional analysis and Business Use Cases (BUC) analysis. A schematic representation of the product/service architecture and a simplification of the real world is allowed by functional analysis, as it is able to fully represent the product and service modules and make the analyst choose the desired level of detail from time to time. Subsequently, BUC is adopted to identify the involved actors, their roles and the main activities.

Step 3. Definition of the TO-BE use cases and formalization of the TO-BE business scenario by following the previous approach. Functional analysis supports the new module definition in a graphical way and the estimates of the connections between new and old modules. After that, functional diagrams are shifted into BUC diagrams and the new tools and systems are identified.

Step 4. Elicitation of the business requirements to shift from PLM to SLM from both the process and service viewpoint on the basis of the TO-BE BUC diagrams. BUC diagrams analysis allows the main differences between AS-IS and TO-BE use cases to be easily identified and the new technological tools and system infrastructures required by the new service-oriented scenario to be quickly defined.

Step 5. Requirements weighting according to the specific context of use. It adopts Participatory Design techniques to make all the companies express a weight for each identified requirement according to the relative importance for the specific role in the ecosystem. In this way, the RE can be weighted according to the needs of each business network partner and can extend to an industrial chain or a group of companies interested in the same business. Indeed, the product manufacturer is usually neither a service provider nor a service market operator, so it will need to have some partners to carry out some specific activities. 


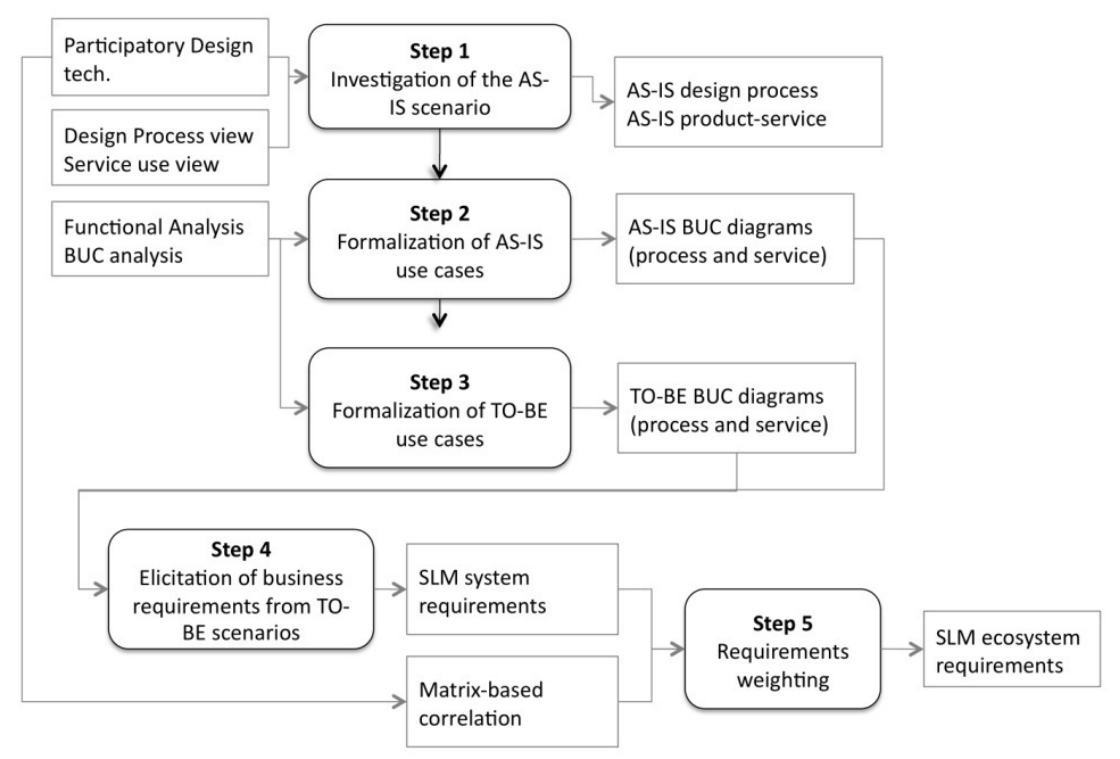

Fig. 1. Overview of the adopted research method

\section{The Industrial Case Study}

\subsection{The Indesit Test Case}

The case study has been realized in collaboration with Indesit Company Spa, an Italian company which is a world leader in the design and production of household appliances and home care devices. Indesit products are intended for different home areas: from cooking, to washing and drying, dish care, and cooling. The company is organized in a traditional hierarchical structure and adopts a product-oriented development process. Collaboration with other organizations is focused on the design of innovative components for its new products (co-design with the design and supply-chain), and the reduction of production time and cost (collaboration with supplier). Co-marketing actions are rare and not really exploited.

In this context the case study starts from an attractive challenge: Could Indesit move from a product-centred view to a service-centred view? Could Indesit no longer sell washing machines or fridges but the services connected with their use? How could this be done? In order to face such a challenge, the authors suggested applying the proposed methodology and verify how to shift from PLM to SLM. Attention has been focused on a flagship product from Indesit: the washing machine. This product has been analyzed in the current use and design process and then projected into the new perspective to define a feasible TO-BE situation where a set of services is added to the AS-IS product. The test case is related to its use and it can be defined as "Washing Machine use at home". Table 1 describes the test case by considering two 
distinct but complementary perspectives: current and desired situations. The last column contains current actors in regular text and future actors in parenthesis, able to carry out the desired scenario.

Table 1. Description of the use case

\begin{tabular}{|l|l|}
\hline $\begin{array}{l}\text { Business Use } \\
\text { Case }\end{array}$ & "Washing Machine use at home" \\
\hline $\begin{array}{l}\text { Current } \\
\text { Functionality }\end{array}$ & $\begin{array}{l}\text { 1. Washing clothes: inserting soap, inserting clothes, selecting washing } \\
\text { program, washing clothes, extracting clothes, drying clothes }\end{array}$ \\
\hline $\begin{array}{l}\text { Desired } \\
\text { Functionality }\end{array}$ & $\begin{array}{l}\text { 1. Support to current functionalities: automatic soap loading, automatic } \\
\text { selection of the best washing cycle, etc. } \\
\text { 2. Improvement of the washing safety and quality: control of washing } \\
\text { results, damage and risks, noise reduction, etc. } \\
\text { 3. Provision of new controls of the WM functioning: } \\
\text { a. Analysis, provisioning and optimization of energy consumption, water } \\
\text { consumption, soap consumption, etc. } \\
\text { b. Monitoring the users' habits } \\
\text { c. Provision of new services oriented to the home ecosystem }\end{array}$ \\
\hline $\begin{array}{l}\text { Stakeholders/ } \\
\text { Systems }\end{array}$ & $\begin{array}{l}\text { Consumer, Home } \\
\text { (Indesit Marketing Staff, Indesit Service Centre, Emergency Centre) }\end{array}$ \\
\hline
\end{tabular}

\subsection{AS-IS Scenario}

From functional analysis and BUC analysis, the authors represented the AS-IS situation by a set of diagrams (black-boxes, functional diagrams, BUC diagrams): they aim to clearly and simply define the main actors involved, the basic flow of actions and the system or tools adopted to do that. Trigger events, assumptions and business rules are also defined according to a structure template.

The analysis of the "Washing Machine use at home" considered both the customer's actions and the home actions, which are automatically carried out by the customer's home and/or the washing machine (WM). The main goal is washing dirty clothes in a correct, efficient and proper way. The goal can be considered the same for both customer and company viewpoints. Figure 2 shows the functional analysis (A) and the BUC diagram at the higher level of detail (B). Each action has been further investigated in the study.

The analysis demonstrates that the AS-IS scenario is strongly product-oriented as business processes are currently based on the product development process. As a consequence, first is the product then the service: it means that services are added to an existing product by minor changes, they are managed as product add-ons and are realized by adding new HW-SW elements to the product. It implies that product and services are conceived and designed in a separate way so that the service ideation process is parallel to the development one. 


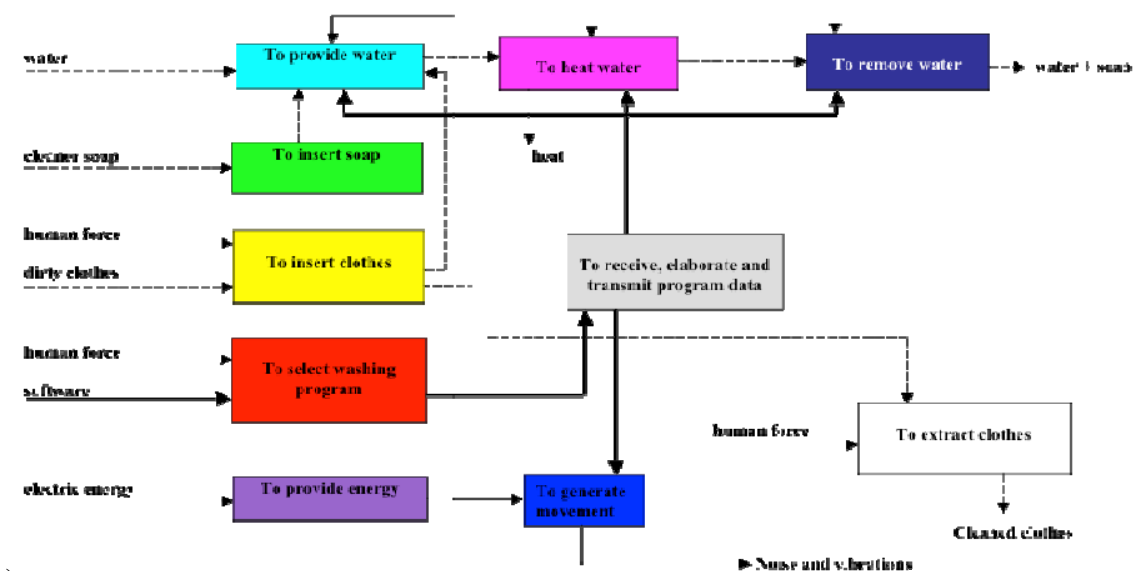

A)

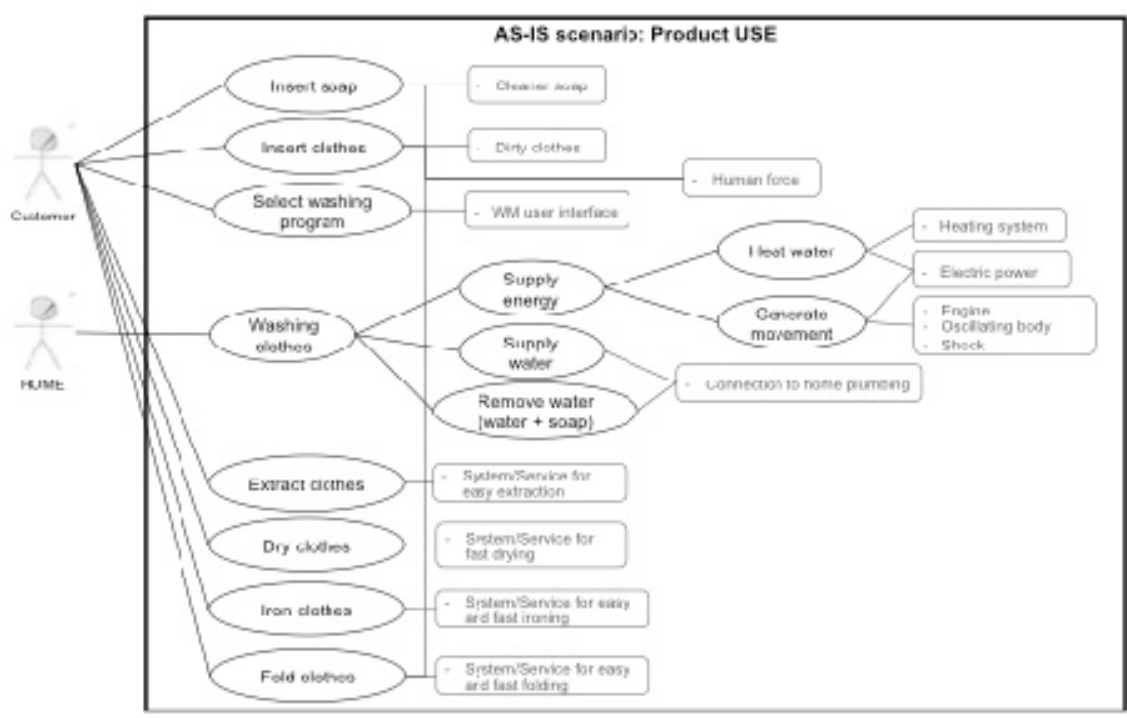

Fig. 2. AS-IS scenario diagrams (level 1)

\subsection{TO-BE Scenario}

TO-BE scenario is focused on services and on the idea of selling services instead of products. In the short term, Indesit continues to sell also products in a Product+Service perspective. However, it is oriented towards a Product2Service solution. The TO-BE scenario no longer includes a specific home function (washing clothes, washing dishes, cooking, cooling, etc.) but a set of functions creating a home-based system which is characterized by two emerging trends: energy efficiency and Ambient Assisted Living. These trends are external and completely out of the Indesit control. As a consequence, the TO-BE scenario starts from the analysis of users' needs and their interpretation to define new solutions and methods of use. 
In this context, the test case "Washing Machine use at home" moves towards the "desired functionalities" of Table 1 and aims to implement a set of assistive services to make the WM more user-friendly and carefree. This means adding to the traditional washing action a list of new functions involving the entire home items. They will be related to efficient energy management, smart and remote maintenance, control of home safety and users' safety at home, mobile information services, household functioning planning and remote scheduling, and new solutions to improve current performances (fast drying, assistive load-unload tools, water reuse system, etc.).

Figure 3 represents the first level of the BUC analysis diagram that contains the main identified actions and the required systems and tools. Functions in round boxes represent a different service offered. It has been defined starting from the AS-IS BUC diagram and proposes new methods for use for future applications adopting a brainstorming approach. After defining level 1, each function has been described in detail (level 2 and level 3). Going deep in the analysis allows necessary HW-SW tools and infrastructures to be identified. Figure 4 shows an example related to remote maintenance. The final goal is the creation of a home-based system, controlled, monitored and connected to the Internet. In this way, it is accessible from the web by the customers as well as the companies' operators. The TO-BE ecosystem will be constituted by Indesit as WM producer and by some business partners, who provide the additional services. Furthermore, it is worth wondering how the new scenario can be properly managed and how new services will be designed, developed and delivered. Such questions can help to identify additional tools or systems.

\subsection{Requirements Elicitation to Create the Indesit Value Chain}

Three external partners have been involved in the proposed case study: a company providing on-site maintenance, a company providing health \& safety services, and a software house developing and delivering mobile applications. Obviously there can be more that one company for addressing large areas, (e.g. USA, North Europe, East Europe, etc.).

Requirements are collected and then properly weighted according to a 5-point Likert scale. Weights have been expressed by the managers of the involved companies according to their skill and expertise.

Table 2 sums the main results for the four partners involved. Three classes of requirements are investigated: washing machine requirements (connected with the product use), SW requirements (that make the machine communicate with remote services and allows services to be provided), infrastructure requirements (referring to the technological system to be created), and additional ones (connected to some specific functions e.g. water reuse).

The most relevant requirements can be considered as crucial aspects to implement the desired SLM-based platform (in bold). They are preliminary and they could be improved by a further analysis stage. 


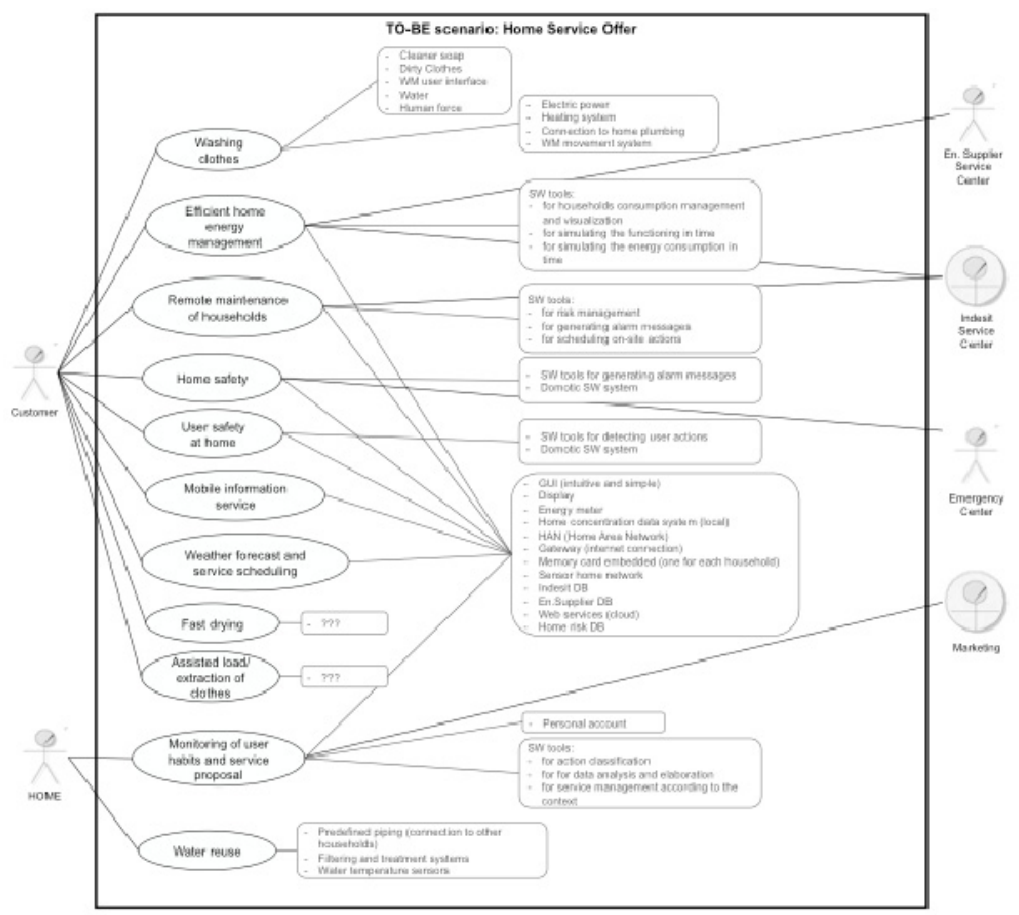

Fig. 3. TO-BE scenario diagrams (level 1)

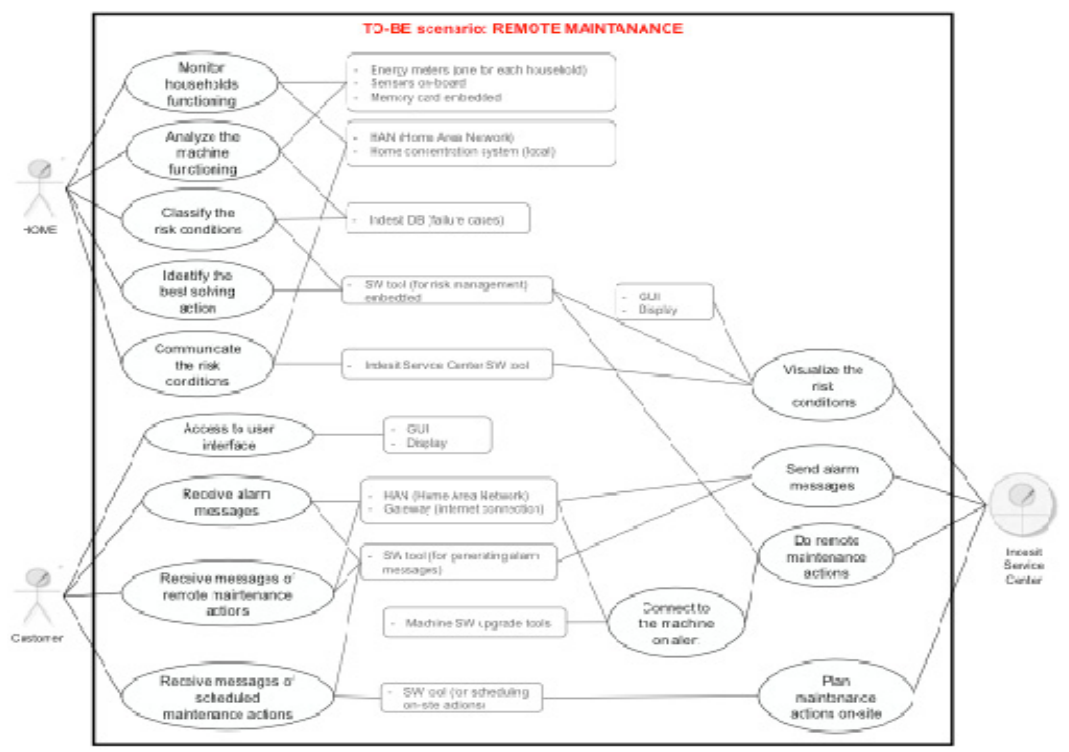

Fig. 4. Example of TO-BE scenario diagrams (level 2): remote maintenance 
Table 2. Requirements weighting according to the Indesit ecosystem

\begin{tabular}{|c|c|c|c|c|c|}
\hline & Indesit & Partner 1 & Partner 2 & Partner 3 & Average data \\
\hline \multicolumn{6}{|l|}{ WM requirements } \\
\hline cleaner soap & 5 & 1 & 1 & 1 & 2,00 \\
\hline dirty clothes & 5 & 1 & 1 & 1 & 2,00 \\
\hline user interface & 5 & 1 & 1 & 1 & 2,00 \\
\hline water & 5 & 1 & 1 & 1 & 2,00 \\
\hline human force & 5 & 1 & 1 & 1 & 2,00 \\
\hline electric power & 5 & 1 & 1 & 1 & 2,00 \\
\hline heating system & 5 & 1 & 1 & 1 & 2,00 \\
\hline connection to home plumbing & 5 & 1 & 1 & 1 & 2,00 \\
\hline WM movement system & 5 & 1 & 1 & 1 & 2,00 \\
\hline \multicolumn{6}{|l|}{ SW requirements } \\
\hline tool for household consumption control & 4 & 5 & 4 & 4 & 4,25 \\
\hline tool for simulating household functioning & 3 & 5 & 3 & 4 & 3,75 \\
\hline tool for simulating energy consumption & 3 & 5 & 3 & 4 & 3,75 \\
\hline tool for risk management & 2 & 5 & 5 & 5 & 4,25 \\
\hline tool for generating alarm message & 3 & 4 & 5 & 5 & 4,25 \\
\hline tool for scheduling on-site actions & 2 & 5 & 4 & 4 & 3,75 \\
\hline tool for detecting user actions & 2 & 4 & 5 & 4 & 3,75 \\
\hline tool for user action classification & 2 & 2 & 5 & 2 & 2,75 \\
\hline tool for data analysis and elaboration & 5 & 4 & 5 & 2 & 4,00 \\
\hline tool for service management & 2 & 5 & 5 & 2 & $\mathbf{3 , 5 0}$ \\
\hline domotic SW system (centralized) & 2 & 4 & 5 & 5 & 4,00 \\
\hline \multicolumn{6}{|l|}{ Infrastructure requirements } \\
\hline GUI (centralized) & 5 & 5 & 4 & 1 & 3,75 \\
\hline display & 5 & 2 & 2 & 1 & 2,50 \\
\hline energy meter for appliances & 2 & 5 & 5 & 2 & $\mathbf{3 , 5 0}$ \\
\hline home concentration data system (local) & 2 & 5 & 4 & 1 & 3,00 \\
\hline HAN (Home Area Network) & 2 & 5 & 5 & 5 & 4,25 \\
\hline memory cards (embedded) & 4 & 5 & 5 & 4 & 4,50 \\
\hline sensor home network & 5 & 3 & 5 & 4 & 4,25 \\
\hline Indesit DB (households) & 5 & 5 & 3 & 1 & 3,50 \\
\hline en.supplier DB (energy consumption) & 3 & 5 & 5 & 1 & $\mathbf{3 , 5 0}$ \\
\hline home risk DB & 3 & 4 & 5 & 1 & 3,25 \\
\hline personal account & 1 & 3 & 3 & 5 & 3,00 \\
\hline web services & 1 & 5 & 4 & 5 & 3,75 \\
\hline \multicolumn{6}{|l|}{ Water reuse requirements } \\
\hline predefined piping & 4 & 1 & 1 & 1 & 1,75 \\
\hline filtering and treatment system & 4 & 1 & 1 & 1 & 1,75 \\
\hline sensors for water control (temperature, etc.) & 4 & 1 & 1 & 1 & 1,75 \\
\hline$\cdots$ & & & & & \\
\hline
\end{tabular}

- $\quad$ Roles: Indesit (WM producer), Partner 1 (on-site maintenance provider), Partner 2 (H\&S provider), Partner 3 (mobile application provider)

\section{Conclusions}

This paper presents a study on the adoption of a service-oriented approach and proposes a methodology to shift from PLM to SLM. The case study is directly taken from a prominent industrial case referring to Indesit Company. It moves from traditional selling based on the product (i.e. washing machine) to a new marketing idea based on a wide home service offer. Services include predictive maintenance 
facilities, rationale control of the energy consumption, monitoring the users' habits to infer the best-suited options and to predict new useful functions and services at the same time, and more. For each service, BUC analysis allows the main systems and tools to be defined and then weighted according to the needs of the ecosystem partners. The test case demonstrates how to identify the new HW-SW architecture to shift form PLM to SLM.

The main novelties of the proposed approach are: the combination of functional analysis, BUC analysis and traditional RE techniques based on Participatory Design, which are generally used separately, and the adoption of a dual perspective considering both the design process and the service use. The combination of three techniques guarantees a more comprehensive analysis and involves numerous actors in product modules and service tools definition. The paper extends the latest research in ProductService area by adopting modelling techniques for a new purpose (i.e. modelling not a product but a Product-Service System) and providing a concrete case study where the approach is concretely used for strategic decision-making. The proposed approach is definitely general, at least within a manufacturing context of use: indeed, functional and BUC analysis can be easily applied to any other physical product which has a modular architecture and satisfies a specific functions by adopting energy, material and information flows (e.g. from other home appliances to game and entertainment devices, to consumer durable goods, till industrial machines, robotic devices and applications and many more. Limitations refer to the high level of product and service knowledge required to carry out a valuable AS-SI and TO-BE analysis as the adopted tools are quite unstructured and they are not able to guide the user in product-service modelling.

The expected benefits from the full adoption of the methodology and SLM-based ecosystem will be diverse. For Indesit it is a chance to innovate its products by proposing new services based on users' needs and habits, and to mix Indesit know-how with that of its partners. For the business partners it is a possibility to obtain useful data about users' needs to specify new products or to enable shared initiatives with Indesit. For final users it is the availability of a set of information services declined on their own habits and preselected upon their own needs. Future work will be addressed to the test case implementation and identification of a solid roadmap to support the company and drive the change from PLM to SLM perspective. The following step will be focused on the real introduction of the SLM approach in the specific industrial scenario.

\section{References}

1. Services Sciences, Management and Engineering, IBM Research, http://www . research.ibm.com/ssme/services.shtml/

2. Van Ark, B., Broersma, L., Den Hertog, P.: Services Innovation, Performance and Policy: A Review, Research Series No. 6, Directorate-General for Innovation, Ministry of Economic Affairs, The Hague (2003)

3. Balin, S., Giard, V.: A process oriented approach to service concepts. 8ème Conférence Internationale de Génie Industriel. Tarbes, France (2009) 
4. Ferrario, R., Guarino, N.: Towards an Ontological Foundation for Services Science. In: Domingue, J., Fensel, D., Traverso, P. (eds.) FIS 2008. LNCS, vol. 5468, pp. 152-169. Springer, Heidelberg (2009)

5. Terzidis, O., Barros, A., Friesen, A., Oberle, D.: The Internet of Services and USDL. Handbook of Service Description: USDL and its Methods, ch. 1, pp. 1-16. Springer (2012)

6. Furrer, O.: Le rôle stratégique des "services autour des produits" ». Revue Française de Gestion, 113, pp. 98-108 (2007)

7. SUSPRONET final report, http: / / www. suspronet.org/

8. Thoben, K.D., Jagdev, H., Eschenbaecher, J.: Extended Products: Evolving Traditional Product Concepts. In: The 7th International Conference on Concurrent Enterprising: Engineering the Knowledge Economy through Cooperation, Bremen, June 27-29 (2001)

9. Byrne, J.A., Brandt, R., Port, O.: The virtual corporation. The company of the future will be ultimate in adaptability. In: Business Week, pp. 36-40 (1993)

10. Bernus, P.: Modelling and methodologies for enterprise integration. In: Proc. of the IFIP TC5 Working Conference on Models and Methodologies for Enterprise Integration, Queensland, Australia. Edited with Laszlo Nemes (1995)

11. Nuseibeh, B., Easterbrook, S.: Requirements Engineering: A Roadmap, International Conference in Software Engineering. In: Proceedings of the Conference on the Future of Software Engineering, pp. 35-40. ACM Publishers, Limerick (2000)

12. Schlosser, C., Jones, S., Maiden, N.A.M.: Using a Creativity Workshop to Generate Requirements for an Event Database Application. In: Paech, B., Rolland, C. (eds.) REFSQ 2008. LNCS, vol. 5025, pp. 109-122. Springer, Heidelberg (2008)

13. Zarvić, N.: 1st User Requirements Analysis for EI and EC, COIN IP (Enterprise Collaboration and Enterprise Interoperability), Deliverable D6.1.1a (2008)

14. Stein, B.: Design problem solving by functional abstraction. In: Proc. of the 16th Workshop Planen und Konfigurieren, Freiburg (2002)

15. Cockburn, A.: Structuring Use Cases with Goals. Journal of Object-Oriented Programming (1997)

16. UML Specification: V1.3 Alpha R5 (1999), http: / /www . rational.com/ 